ARTICLE

https://doi.org/10.1038/s41467-019-13682-5

\title{
A hierarchically assembled 88-nuclei silver-thiacalix[4]arene nanocluster
}

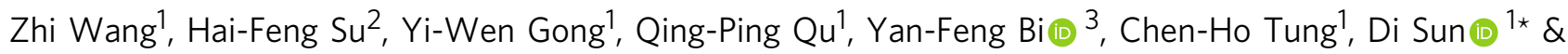 \\ Lan-Sun Zheng ${ }^{2}$
}

Thiacalix[4]arenes as a family of promising ligands have been widely used to construct polynuclear metal clusters, but scarcely employed in silver nanoclusters. Herein, an aniontemplated $\mathrm{Ag}_{88}$ nanocluster (SD/Ag88a) built from $p$-tert-butylthiacalix[4]arene $\left(\mathrm{H}_{4} \mathrm{TC} 4 \mathrm{~A}\right)$ is reported. Single-crystal $X$-ray diffraction reveals that $C_{4}$-symmetric $\mathrm{SD} / \mathrm{Ag} 88$ a resembles a metal-organic super calix comprised of eight TC4A ${ }^{4-}$ as walls and 88 silver atoms as base, which can be deconstructed to eight $\left[\mathrm{CrO}_{4} @ \mathrm{Ag}_{11}(\mathrm{TC} 4 \mathrm{~A})(\mathrm{EtS})_{4}(\mathrm{OAc})\right]$ secondary building units arranged in an annulus encircling $\mathrm{CrO}_{4}{ }^{2-}$ in the center. Local and global anion template effects from chromates are individually manifested in SD/Ag88a. The solution stability and hierarchical assembly mechanism of SD/Ag88a are studied by using electrospray mass spectrometry. The $\mathrm{Ag}_{88}$ nanocluster represents the highest nuclearity metal cluster capped by $\mathrm{TC}_{\mathrm{A}} \mathrm{A}^{4-}$. This work not only exemplify the specific macrocyclic effects of $\mathrm{TC}_{4} \mathrm{~A}^{4-}$ in the construction of silver nanocluster but also realize the shape heredity of $\mathrm{TC} 4 \mathrm{~A}^{4-}$ to overall silver super calix.

\footnotetext{
${ }^{1}$ Key Laboratory of Colloid and Interface Chemistry, Ministry of Education, School of Chemistry and Chemical Engineering, State Key Laboratory of Crystal Materials, Shandong University, Jinan 250100, People's Republic of China. ${ }^{2}$ State Key Laboratory for Physical Chemistry of Solid Surfaces and Department of Chemistry, College of Chemistry and Chemical Engineering, Xiamen University, Xiamen 361005, People's Republic of China. ${ }^{3}$ College of Chemistry, Chemical Engineering and Environmental Engineering, Liaoning Shihua University, Fushun 113001, People's Republic of China. *email: dsun@sdu.edu.cn
} 
D ue to the esthetic structures and a plethora of promising properties, silver nanoclusters have emerged as a hot topic garnering great interests over the last decade. ${ }^{1-12}$ However, their synthetic chemistry is still in the embryo, and trial and error is now the most popular synthetic routine. Regarding their assembly, protecting ligand is one of the most important prerequisites we must consider, and the widely recognized candidates are thiols, alkynes, and phosphines, or their combinations. ${ }^{13-15}$ Later, the advancements of anion template strategy ${ }^{16-19}$ and geometric polyhedral principle ${ }^{20-22}$ promote the rational design and synthesis of silver nanoclusters to a higher level. Compared with the above-mentioned organic ligands bearing singlecoordination site, macrocyclic ligands with multiple preorganized coordination sites are much more desired in the construction of silver nanoclusters because of their reinforcement effect originating from the cooperative coordination of multiple binding groups. These considerations are reminiscent of "third generation" calixarenes-thiacalix[4]arenes, which are macrocyclic tetramers of phenols joined by sulfur atoms ${ }^{23}$ and have been recognized as a family of good ligands in the assembly of polynuclear metal clusters and cages. ${ }^{24-27}$ Based on the multiple coordination sites of $-\mathrm{OH}$ and $-\mathrm{S}$ - groups on them, a series of large metal nanoclusters or nanocages, including $\mathrm{Co}_{16}, \mathrm{Co}_{24}$, $\mathrm{Mn}_{24}, \mathrm{Co}_{32}, \mathrm{Ni}_{32}$, and $\mathrm{Ni}_{40}$, have been reported by Liao and Hong groups. ${ }^{28-33}$ However, thiacalix[4]arene-protected silver nanocluster is still rudimentary, and only two closely related p-tert-butylthiacalix[4] arene $\left(\mathrm{H}_{4} \mathrm{TC} 4 \mathrm{~A}\right)$-capped reductive $\mathrm{Ag}_{34}$ and $\mathrm{Ag}_{35}$ nanoclusters have been reported. ${ }^{34,35}$ Although the coordination sites of $\mathrm{H}_{4} \mathrm{TC} 4 \mathrm{~A}$ favor to support silver nanoclusters, the bulky skeleton of $\mathrm{H}_{4}$ TC4A also brings a big challenge in growth of single crystals, which is very crucial to understand the structural details of both metal core and metal-ligand interface.

Except for the ligand selection, oxoanion template plays another dominant role in constructing silver nanoclusters due to the strong directional effect arising from $\mathrm{Ag}-\mathrm{O}$ interaction. ${ }^{36-41}$ In most cases of anion-templated assembly, oxoanions commonly exert the global effect that means the metal ions aggregate around them in a roughly chaotic fashion without any precedence. As we know, shuttlecock-like $\left\{\mathrm{M}_{4}(\mathrm{TC} 4 \mathrm{~A})\right\}(\mathrm{M}=\mathrm{Mn}, \mathrm{Fe}, \mathrm{Co}$, and $\mathrm{Ni})$ is a very common secondary building unit (SBU) in $\mathrm{TC}^{4} \mathrm{~A}^{4-}$-capped metal nanoclusters; ${ }^{42}$ however, we do not know what is the SBU if metal is switched to silver in the presence of the anion template. More importantly, we are also unclear that whether the as-formed $\left\{\right.$ (template)@ $\left.\mathrm{Ag}_{\mathrm{x}}(\mathrm{TC} 4 \mathrm{~A})\right\}$ SBUs can be further reorganized around the oxoanion template again to form the hierarchical motif. Thus, correlating the SBUs and the final structure of $\mathrm{TC}_{4} \mathrm{~A}^{4-}$-capped silver nanocluster is very important for understanding their syntheses and assembly mechanism.

Considering the rich advantages of $\mathrm{H}_{4} \mathrm{TC} 4 \mathrm{~A}$ in coordination chemistry and the powerful anion template effect in silver nanoclusters, we are extending our researches to combine them together in the synthesis of silver nanoclusters. Herein, we present a $C_{4}$-symmetric silver nanocluster $\left(\mathrm{K}_{2}\left[\left(\mathrm{CrO}_{4}\right)_{9} @ \mathrm{Ag}_{88}(\mathrm{TC} 4 \mathrm{~A})_{8}\right.\right.$ $\left.\left.(\mathrm{EtS})_{32}(\mathrm{OAc})_{8}\right] \cdot 8 \mathrm{CH}_{3} \mathrm{CN} \cdot 4 \mathrm{DMF} ; \mathrm{SD} / \mathrm{Ag88a}\right)$ with a super calix shape containing the $\left[\mathrm{CrO}_{4} @ \mathrm{Ag}_{11}(\mathrm{TC} 4 \mathrm{~A})(\mathrm{EtS})_{4}(\mathrm{OAc})\right]$ as SBU. Eight SBUs are further cyclized into an $\mathrm{Ag}_{88}$ cluster around a central $\mathrm{CrO}_{4}{ }^{2-}$. This silver nanocluster is the highest-nuclearity metal cluster capped by $\mathrm{TC}_{4} \mathrm{~A}^{4-}$. The structural features including the special ligand effect, local and global anion template effects, as well as the hierarchical assembly in SD/Ag88a will be discussed in detail.

\section{Results}

Structures of SD/Ag88a and SD/Ag88b. Briefly, SD/Ag88a was facilely prepared by the reaction of (EtSAg) $)_{n} \mathrm{H}_{4} \mathrm{TC} 4 \mathrm{~A}, \mathrm{AgOAc}$,

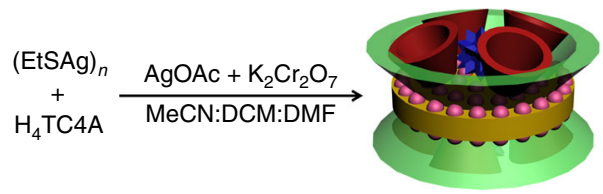

Fig. 1 Synthetic route for super calix of SD/Ag88a. DCM = dichloromethane, $\mathrm{DMF}=\mathrm{N}, \mathrm{N}$-dimethylformamide. Color legends for objects: red: $\mathrm{H}_{4}$ TC4A ligand; green: super calix; pink: silver atom; blue: $\mathrm{CrO}_{4}{ }^{2-}$; yellow: the base of super calix.

and $\mathrm{K}_{2} \mathrm{Cr}_{2} \mathrm{O}_{7}$ in the mixed solvent system containing acetonitrile, dichloromethane, and DMF at room temperature (Fig. 1). The red prism crystals can be crystallized after 2 weeks and collected together by filtration as bulk samples $(\sim 10 \%)$. The higher-yield synthesis of SD/Ag88a can be achieved using solvothermal reaction at $65^{\circ} \mathrm{C}(\sim 40 \%)$. The AgOAc in the synthesis of SD/Ag88a is very crucial because we have tried the other eight different silver salts available in our laboratory, including $\mathrm{AgBF}_{4}$, $\mathrm{CF}_{3} \mathrm{COOAg}, \mathrm{CH}_{3} \mathrm{SO}_{3} \mathrm{Ag}, \mathrm{CF}_{3} \mathrm{SO}_{3} \mathrm{Ag}, \mathrm{AgNO}_{3}, \mathrm{AgSbF}_{6}, \mathrm{PhCOOAg}$, and $p$-TOSAg, but none of them can produce SD/Ag88a. Auxiliary EtS ${ }^{-}$ligand also shows steric hindrance-related influence on the formation of SD/Ag88a because other larger alkylthiols such as ${ }^{t} \mathrm{BuSH}$ or ${ }^{i} \mathrm{PrSH}$ cannot produce SD/Ag88a under the same assembly condition. Of note, by mixing AgOAc with $\mathrm{AgSbF}_{6}$ in this system, we can isolate a similar $\mathrm{Ag}_{88}$ cluster $\left(\mathrm{K}_{2}\left[\left(\mathrm{CrO}_{4}\right)_{9} @ \mathrm{Ag}_{88}(\mathrm{TC} 4 \mathrm{~A})_{8}(\mathrm{EtS})_{32}(\mathrm{OAc})_{8}\left(\mathrm{CH}_{3} \mathrm{CN}\right)\right] \cdot 8 \mathrm{CH}_{3} \mathrm{CN} ; \mathrm{SD} /\right.$ Ag88b), but crystallized in monoclinic $P 2_{1} / c$ space group. The detailed structure diagrams for SD/Ag88b are shown in Supplementary Fig. 1. A series of characterization techniques such as single-crystal X-ray diffraction (SCXRD), powder X-ray diffraction (PXRD), Fourier transform-infrared spectroscopy (FTIR), UV-Vis spectroscopy, thermogravimetric analysis (TGA), dynamic light scattering (DLS), energy-dispersive X-ray spectroscopy (EDS), and transmission electron microscopy (TEM) were used in this system (Supplementary Figs. 7-17).

X-ray diffraction analyses on single crystals (Supplementary Fig. 18) of SD/Ag88a and SD/Ag88b revealed that they crystallize in tetragonal $P 4 / n$ and monoclinic $P 2_{1} / c$ space groups, respectively (Supplementary Table 1). More structural diagrams and crystallographic data plots for them are shown in Supplementary Figs. 19-29. The composition of SD/Ag88a was determined as $\left\{\mathrm{K}_{2}\left[\left(\mathrm{CrO}_{4}\right)_{9} @ \mathrm{Ag}_{88}(\mathrm{TC} 4 \mathrm{~A})_{8}(\mathrm{EtS})_{32}(\mathrm{OAc})_{8}\right] \cdot 8 \mathrm{CH}_{3} \mathrm{CN} \cdot 4 \mathrm{DMF}\right\}$. The composition of SD/Ag88b has one more coordinated $\mathrm{CH}_{3} \mathrm{CN}$ on the surface of the cluster compared with SD/Ag88a. The asymmetric unit of SD/Ag88a contains a quarter of $\mathrm{Ag}_{88}$ cluster and a crystallographic fourfold axis passes through $\mathrm{Cr}$ atom of the central $\mathrm{CrO}_{4}{ }^{2-}$, whereas no crystallographic symmetry element coincides with the $\mathrm{Ag}_{88}$ cluster of $\mathbf{S D} / \mathbf{A g 8 8 b}$, so a complete molecule was observed in the asymmetric unit. As a result, the overall 88-silver metallic framework of SD/Ag88b is more distorted than that of SD/Ag88a.

Due to the structural similarity between SD/Ag88a and SD/ Ag88b, we just describe and discuss their structures below by taking SD/Ag88a as a representative. As shown in Fig. 2, SD/ Ag88a looks like a super calix composed of 88 silver atoms, 32 $\mathrm{EtS}^{-}, 8 \mathrm{TC}^{4} \mathrm{~A}^{4-}, 8 \mathrm{OAc}^{-}$, and $9 \mathrm{CrO}_{4}{ }^{2-}$ anions. Among them, 88 silver atoms and $8 \mathrm{TC} \mathrm{A}^{4-}$ ligands roughly constitute the base and wall of the super calix, respectively. The equator diameter and the height of SD/Ag88a are 2.2 and $1.1 \mathrm{~nm}$, respectively, by removing the organic shell.

The metallic skeleton of 88 silver atoms can be divided into eight $\mathrm{CrO}_{4}{ }^{2-}$-templated $\mathrm{Ag}_{11}$ SBUs and each of them is capped by one TC4 $\mathrm{A}^{4-}$ with a cone-shaped conformation to form an 

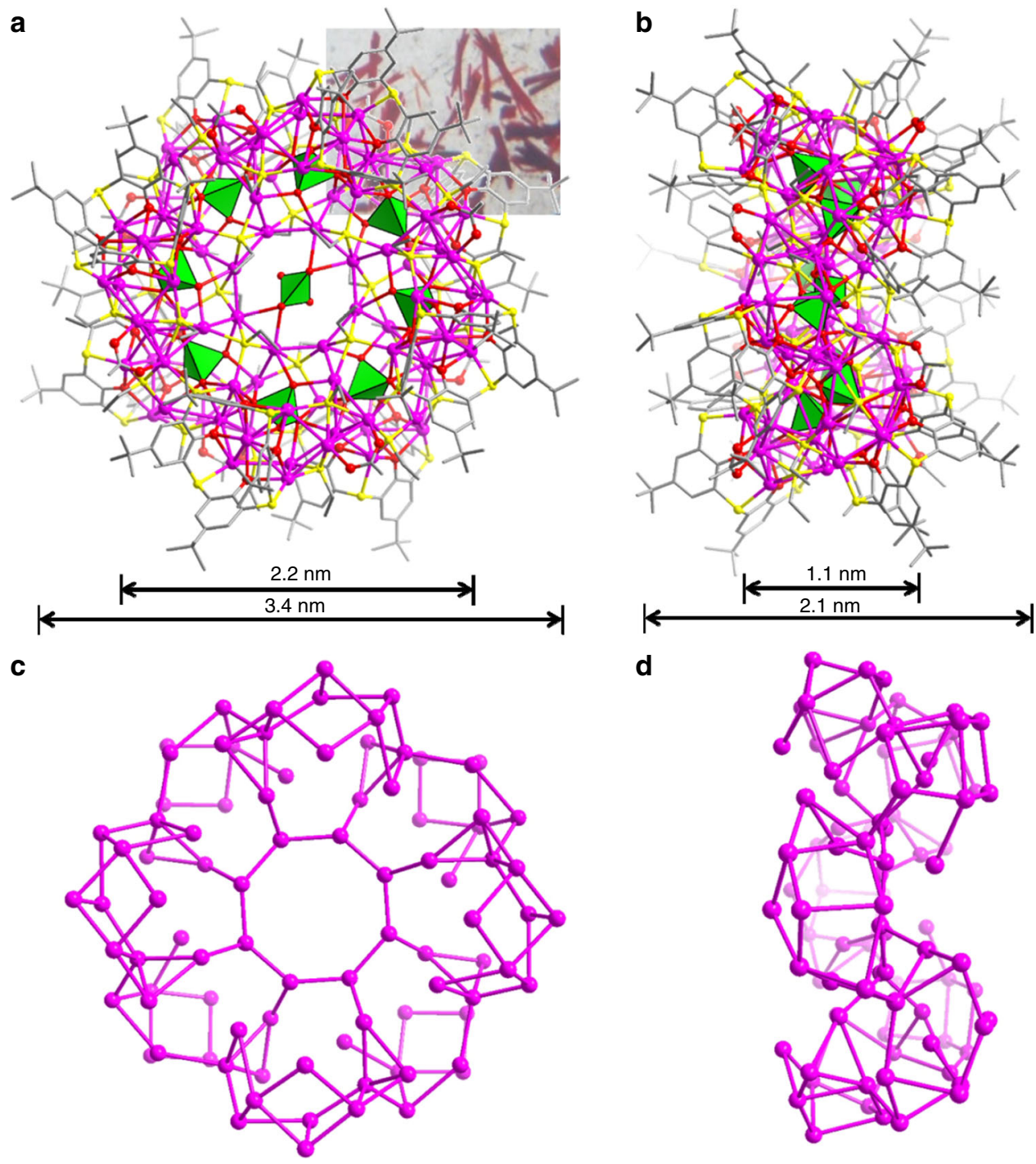

Fig. 2 Single-crystal X-ray structure of SD/Ag88a. a and $\mathbf{b}$ Total structures of $\mathrm{Ag}_{88}$ super calix viewed along two orthogonal directions. The inset in Fig. $2 \mathrm{a}$ is the photograph of crystals of SD/Ag88a taken by using a digital camera under the microscope. $\mathbf{c}$ and $\mathbf{d}$ The skeletal structure of SD/Ag88a by removing all organic ligands and anion templates viewed along two orthogonal directions. Color labels: purple, Ag; yellow, S; gray, C; red, O; green polyhedra, $\mathrm{CrO}_{4}{ }^{2-}$.

irregular SBU with a composition of $\left[\mathrm{CrO}_{4} @ \mathrm{Ag}_{11}(\mathrm{TC} 4 \mathrm{~A})\right.$ $\left.(\mathrm{EtS})_{4}(\mathrm{OAc})\right]$ (Fig. 3a). The $\mathrm{CrO}_{4}{ }^{2-}$ plays the local templating effect in such SBU using a $\mu_{10}-\kappa^{3}: K^{3}: K^{2}: K^{2}$ mode. In the asymmetric unit, there are two $\mathrm{Ag}_{11} \mathrm{SBUs}$ fused together with two $\mathrm{TC}^{4} \mathrm{~A}^{4-}$ ligands locating in a nearly perpendicular orientation (Supplementary Fig. 2). In each cavity of $\mathrm{TC}_{4} \mathrm{~A}^{4-}$, one $\mathrm{CH}_{3} \mathrm{CN}$ molecule is encapsulated and its $\mathrm{N}$ atom points out of the bigger opening of TC4A $\mathrm{A}^{4-}$ (Supplementary Fig. 3). The sunken voids formed after removing $\mathrm{CH}_{3} \mathrm{CN}$ molecule from $\mathrm{TC}_{4} \mathrm{~A}^{4-}$ are clearly shown in Supplementary Fig. 4. Two crystallographic unique $\mathrm{TC}_{4} \mathrm{~A}^{4-}$ ligands show different coordination modes using both phenolic hydroxyl and bridging sulfur atoms, $\mu_{6}-\kappa_{0}^{2}: \kappa_{0}^{3}: \kappa_{o}^{3}$ : $\kappa_{o}^{3}: \kappa_{s}^{1}: \kappa_{s}^{1}: \kappa_{s}^{1}: \kappa_{s}^{2}$ (Fig. 3b) and $\mu_{7}-\kappa_{o}^{3}: \kappa_{o}^{3}: \kappa_{o}^{3}: \kappa_{o}^{3}: \kappa_{s}^{1}: \kappa_{s}^{1}: \kappa_{s}^{1}: \kappa_{s}^{2}$ (Fig. 3c). The Ag-O and Ag-S bond lengths related to TC4A ${ }^{4-}$ fall in the ranges of 2.255(5)-2.70(1) $\AA$ and 2.511(5)-2.753(5) $\AA$, respectively (Supplementary Table 2 ). The $\mathrm{OAc}^{-}$uses bidentate bridging $\left(\mu_{2}-\kappa^{1}: \kappa^{1}\right)$ mode to coordinate on the $\mathrm{Ag}_{11} \mathrm{SBU}(\mathrm{Ag}-\mathrm{O}$ : 2.14(2)-2.41(2) $\AA$ ). Two of four EtS- ligands in each SBU adopt $\mu_{4}$ mode to cap on $\mathrm{Ag}_{11}$ SBU (Ag-S: 2.397(5)-2.641(7) $\AA$ ), whereas the other two (one in $\mu_{3}$ and another in $\mu_{4}$ mode) combine with TC4A ${ }^{4-}$ bridges to consolidate the joints between
SBUs (Supplementary Fig. 5). One remaining central $\mathrm{CrO}_{4}{ }^{2-}$ anion $\left(\mu_{4}-\kappa^{2}: \kappa^{2}: \kappa^{0}: \kappa^{0}\right)$ uses the global templating effect to organize eight $\mathrm{Ag}_{11}$ SBUs into an annulus finally (Fig. $3 \mathrm{~d}$ ); thus the best description for SD/Ag88a is $\left\{\mathrm{CrO}_{4} @\left[\mathrm{CrO}_{4} @ \mathrm{Ag}_{11}(\mathrm{TC} 4 \mathrm{~A})\right.\right.$ $\left.\left.(\mathrm{EtS})_{4}(\mathrm{OAc})\right]_{8}\right\}$. Although the $\mathrm{TC}^{4} \mathrm{~A}^{4-}$ ligands effectively cover on SD/Ag88a, we should not neglect the importance of auxiliary small $\mathrm{EtS}^{-}$and $\mathrm{OAc}^{-}$ligands that fill into the coordination unsaturation regions left after $\mathrm{TC}_{4} \mathrm{~A}^{4-}$ coverage. The argentophilic interactions, featured as the Ag $\cdots$ Ag distances shorter than $3.44 \AA$ falling in the range of $2.825(2)-3.418(2) \AA$, reinforce the overall $\mathrm{Ag}_{88}$ skeleton. ${ }^{43-45}$ Although linking cationic shuttlecocklike $\left\{\mathrm{M}_{4}(\mathrm{TC} 4 \mathrm{~A})\right\}(\mathrm{M}=\mathrm{Mn}, \mathrm{Fe}, \mathrm{Co}$, and Ni) SBUs by carboxylates can form a very large nanocage with total metal counts more than $30,{ }^{29}$ there are no $\mathrm{TC} 4 \mathrm{~A}^{4-}$-protected metal clusters with nuclearity higher than 80 ; thus $\mathbf{S D} / \mathbf{A g 8 8 a}$ is the highestnuclearity metal cluster capped by $\mathrm{TC}^{4} \mathrm{~A}^{4-}$. Compared with the known biggest silver cluster, $\left[\mathrm{Ag}_{490} \mathrm{~S}_{188}\left(\mathrm{StC}_{5} \mathrm{H}_{11}\right)_{114}\right],{ }^{15}$ the 88nuclei silver super calix represents a brand-new structure model in the silver cluster family.

The packing of SD/Ag88a is also quite interesting and shown in Fig. 4a, c. The $\mathrm{Ag}_{88}$ super calix is lined in a face-to-face fashion 
a

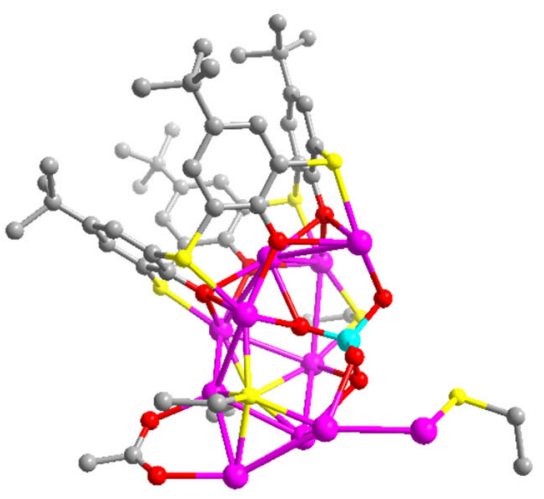

c

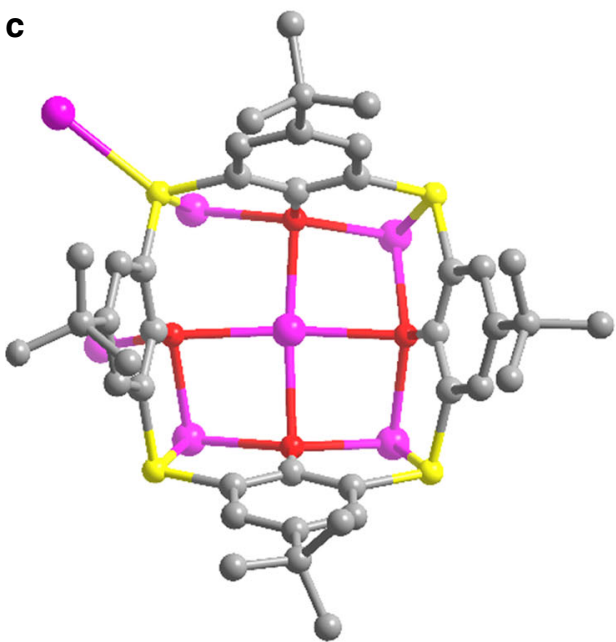

b

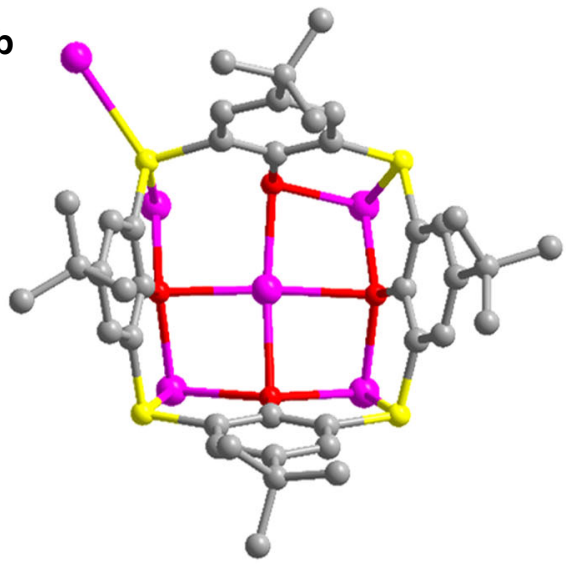

d

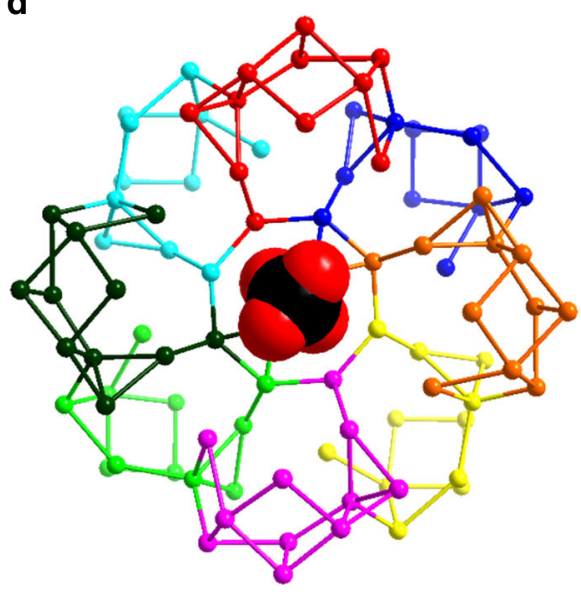

Fig. $3 \mathbf{A g}_{11}$ SBU in SD/Ag88a. a The ball-and-stick mode of the structure of $\left[\mathrm{CrO}_{4} @ \mathrm{Ag}_{11}(\mathrm{TC} 4 \mathrm{~A})(\mathrm{EtS})_{4}(\mathrm{OAc})\right]$ SBU. b, c Two different coordination modes of $\mathrm{TC}_{4} \mathrm{~A}^{4-}$ ligands. Color labels: purple, $\mathrm{Ag}$; yellow, $\mathrm{S}$; gray, $\mathrm{C}$; red, $\mathrm{O}$; cyan, $\mathrm{Cr}$. $\mathbf{d}$ The $\mathrm{Ag}_{88}$ annulus built from eight $\mathrm{Ag}_{11} \mathrm{SBU}_{\mathrm{s}}$ around the central $\mathrm{CrO}{ }_{4}^{2-}$ anion. Eight $\mathrm{Ag}_{11} \mathrm{SBUs}$ are individually colored.

to form a $1 \mathrm{D}$ nanotube running along [001] direction. Such packing is mainly dictated by intercluster van der Waals interaction between $t$-butyl groups on the upper rims and generates some voids as shown in Supplementary Fig. 6. The distance between adjacent two SD/Ag88a nanoclusters is $23.14 \AA$ based on the separation between two Crl atoms. The similar packing was also observed in a chiral lead metal-organic nanotube based on $\beta$-cyclodextrin. ${ }^{46}$ Interestingly, the packing fashion of SD/Ag88b is completely different from that of SD/ Ag88a. The intercluster van der Waals interactions that dominated face-to-side arrangement were found in the packing of SD/Ag88b (Fig. 4b, d). The centroid separation between two $\mathrm{Ag}_{88}$ clusters of $\mathbf{S D} / \mathbf{A g 8 8 b}$ is $26.27 \AA$. The larger separations between clusters indicated their loose packing that may be sensitive to co-crystallized solvents, although no satisfactory structural model for all solvent positions could be determined from SCXRD analysis. The different weight losses in the first step upon heating in $\mathrm{N}_{2}$ stream observed in the TGA curves suggested the different solvent-filling in the crystals (Supplementary Fig. 7a) and the residues after TGA are primarily metallic silver (Supplementary Fig. 7b).

Solution behaviors of SD/Ag88a. Mass spectrometry, DLS, and TEM were utilized to check the solution behavior of SD/Ag88a dissolved in $\mathrm{CH}_{2} \mathrm{Cl}_{2}$. The ESI-MS of SD/Ag88a contains five major isotope-distribution envelops $(\mathbf{1 a}-\mathbf{l e})$ in the $\mathrm{m} / \mathrm{z}$ range lower than
4000 (Fig. 5a). They are trivalent species deduced from the difference $(\Delta m / z=0.33)$ between adjacent isotopic peaks in each envelop. The most dominant envelop centered at $\mathrm{m} / z=3038.487$ (1d) can be assigned to $\left[\left(\mathrm{CrO}_{4}\right)_{4} @ \mathrm{Ag}_{44}(\mathrm{TC} 4 \mathrm{~A})_{4}(\mathrm{EtS})_{16}(\mathrm{OAc})\right]^{3+}($ Calcd. $\mathrm{m} / z=$ 3038.513), which is roughly equal to a half of SD/Ag88a but losing one central $\mathrm{CrO}_{4}{ }^{2-}$, three $\mathrm{OAc}^{-}$anions, and some guest solvent molecules. In other words, the species $\mathbf{1 d}$ is equivalent to four fused $\mathrm{Ag}_{11}$ SBUs after losing three $\mathrm{OAc}^{-}$anions. Based on the isotope distributions, the envelop 1c centered at $\mathrm{m} / z=3009.850$ can be assigned to $\left[\left(\mathrm{CrO}_{4}\right)_{4} @ \mathrm{Ag}_{43}(\mathrm{TC} 4 \mathrm{~A})_{4}(\mathrm{EtS})_{14}(\mathrm{OAc})_{2}\left(\mathrm{CH}_{2} \mathrm{Cl}_{2}\right)\right]^{3+}$ (Calcd. $\mathrm{m} / z=3009.859$ ). Interestingly, the $\mathrm{m} / \mathrm{z}$ spacing between $1 \mathrm{a}$ and $\mathbf{1 c}, \mathbf{1 b}$ and $\mathbf{1 d}$, and $\mathbf{1 d}$ and $\mathbf{1 e}$ is 55.30 or 55.96, which can be attributed to the mass of one AgOAc divided by the charge state of +3 , indicating the coordination-dissociation equilibrium between them involving losing or gaining one $\mathrm{AgOAc}$ unit. In the $\mathrm{m} / \mathrm{z}$ range higher than 4000, we also observed two weak but recognizable peaks centered at 4503.247 (1f) and 4587.207 (1g). After checking the spacing of adjacent isotopic peaks, we found that $\mathbf{1 f}$ and $\mathbf{1 g}$ are divalent species and can be assigned to $\left[\left(\mathrm{CrO}_{4}\right)_{4} @ \mathrm{Ag}_{43}(\mathrm{TC} 4 \mathrm{~A})_{4}(\mathrm{Et}-\right.$ S) $\left.{ }_{16}(\mathrm{OAc})\right]^{2+}$ (1f, Calcd. $\left.m / z=4503.318\right)$ and $\left[\left(\mathrm{CrO}_{4}\right)_{4} @ \mathrm{Ag}_{44}(\mathrm{~T}-\right.$ $\left.\mathrm{C} 4 \mathrm{~A})_{4}(\mathrm{EtS})_{16}(\mathrm{OAc})_{2}\right]^{2+}(\mathbf{l g}$, Calcd. $m / z=4587.277)$, respectively. The detailed formulae of $\mathbf{1 a - 1} \mathbf{g}$ are listed in Supplementary Table 3.

To rule out the possible fragmentation pathway of $\mathrm{Ag}_{88}$ cluster occurred in ESI-MS measurement, we also used DLS and TEM to examine the original $\mathrm{CH}_{2} \mathrm{Cl}_{2}$ solution of SD/Ag88a. Both Supplementary Figs. 8, 9a show some particles with diameters smaller than SD/Ag88a, which clearly suggest that the 
a

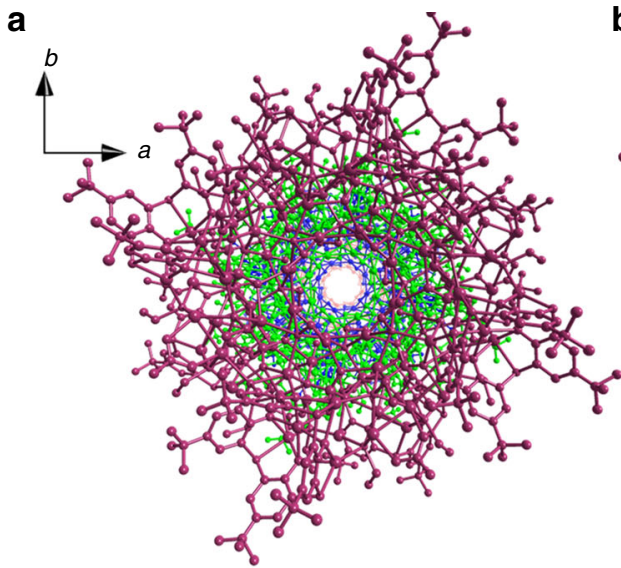

C

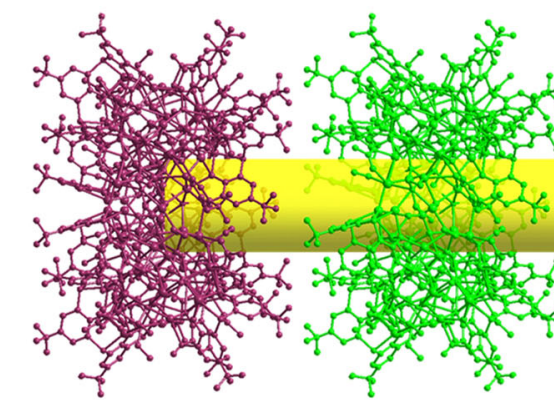

d

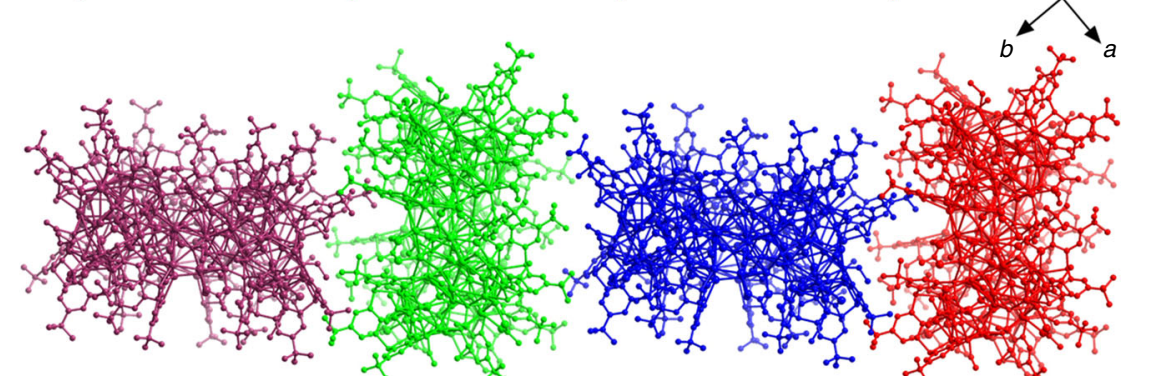

b

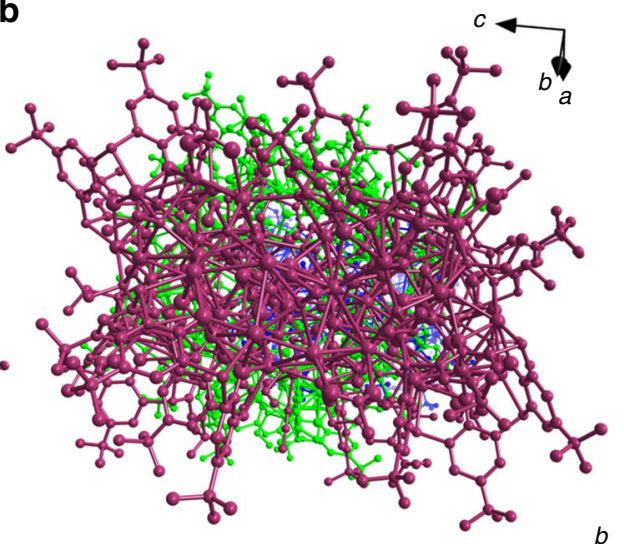

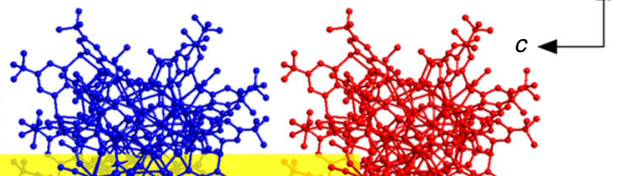
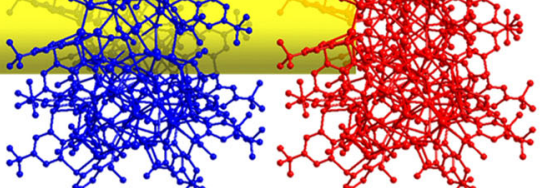
con

Fig. 4 The packing of SD/Ag88a and SD/Ag88b. Top and side views of the $1 D$ array of SD/Ag88a (a, c) and SD/Ag88b (b, d). Different $A g_{88}$ clusters are individually colored. The central $\mathrm{CrO}_{4}{ }^{2-}$ was removed for clarity.

fragmentation happens in the course of dissolution instead of the ESI-MS process. From the above-combined results, we can conclude that (i) partial SD/Ag88a can keep intact but mainly coexists with a half of it in the $\mathrm{CH}_{2} \mathrm{Cl}_{2}$; (ii) the coordination-dissociation equilibria involving few ligands and $\mathrm{AgOAc}$ exist in this system; (iii) the encapsulation of the central $\mathrm{CrO}_{4}{ }^{2-}$ may not happen until the final stage enclosing the overall $\mathrm{Ag}_{88}$ super calix from two halves of $\mathrm{Ag}_{44}$ fragments. Based on the above structural analysis and the cluster fragmentation path revealed by mass spectrometry, we can retrodict a growth route for SD/Ag88a from bowl-like $\mathrm{Ag}_{11} \mathrm{SBU}$, a tetrameric semicircular $\mathrm{Ag}_{44}$ fragment to the final octameric circular $\mathrm{Ag}_{88}$ super calix (Fig. 5b).

UV-Vis spectra and photocurrent response properties. As shown in Fig. 6a, the solid-state UV-Vis spectra of SD/Ag88a, SD/Ag88b, and (EtSAg) ${ }_{n}$ precursor were measured at 250-1000 $\mathrm{nm}$ at room temperature. The (EtSAg) ${ }_{n}$ precursor looks yellow to the naked eye, whereas the SD/Ag88a and SD/Ag88b appear to be dark red. Both SD/Ag88a and SD/Ag88b show similar doublehump absorption profile, one narrow peak at ca. $340 \mathrm{~nm}$, and one broad peak starting from ca. 370 to $800 \mathrm{~nm}$. The absorption peak at $340 \mathrm{~nm}$ can be attributed to the $\mathrm{n} \rightarrow \pi^{*}$ transition of $\mathrm{EtS}^{-}$, as similarly observed in the absorption spectrum of the (EtSAg) precursor. The broad absorption band can be attributed to the charge transfer transition from S $3 p$ to Ag $5 s$ orbitals, which thus cause 240 and $190 \mathrm{~nm}$ redshifts of the absorption edges for SD/ Ag88a and SD/Ag88b, respectively, compared with (EtSAg) The bandgaps of SD/Ag88a, SD/Ag88b, and (EtSAg) ${ }_{n}$ precursor were determined as $1.37,1.48$, and $2.19 \mathrm{eV}$, respectively, according to the Kubelka-Munk function (Supplementary Fig. 10), which indicates that the aggregation of silver atoms into the cluster can influence the bandgap structures that include broadening of the absorption edge and narrowing of the bandgap. In addition, both SD/Ag88a and SD/Ag88b are almost emission silent at both room temperature and liquid nitrogen temperature.

Considering the wide visible light absorption, we performed photocurrent measurements for (EtSAg) ${ }_{n}, \mathbf{S D} / \mathbf{A g 8 8 a}$, and SD/ Ag88b in a typical three-electrode system by coating them on indium-doped $\mathrm{SnO}_{2}$ (ITO) as working electrodes (platinum wire as the assisting electrode and $\mathrm{Ag} / \mathrm{AgCl}$ as the reference electrode) and keeping the bias voltage at $0.6 \mathrm{~V}$. The photocurrent experiments were carried out in a $0.2 \mathrm{M} \mathrm{Na}_{2} \mathrm{SO}_{4}$ aqueous solution under illumination upon on/off cycling irradiation with LED light $(\lambda=420 \mathrm{~nm} ; 50 \mathrm{~W}$; intervals of $10 \mathrm{~s})$. Upon irradiation, photocurrent density increases at $0.16,0.12$, and $0.20 \mu \mathrm{Acm}^{-2}$ for $\left(\right.$ EtSAg) ${ }_{n}$, SD/Ag88a, and SD/Ag88b, respectively (Fig. 6b), which indicates that the SD/Ag88b possesses the best efficiency in the generation and separation of photoinduced electron/hole pairs in ITO electrodes. ${ }^{47}$ The photocurrent density can be still 

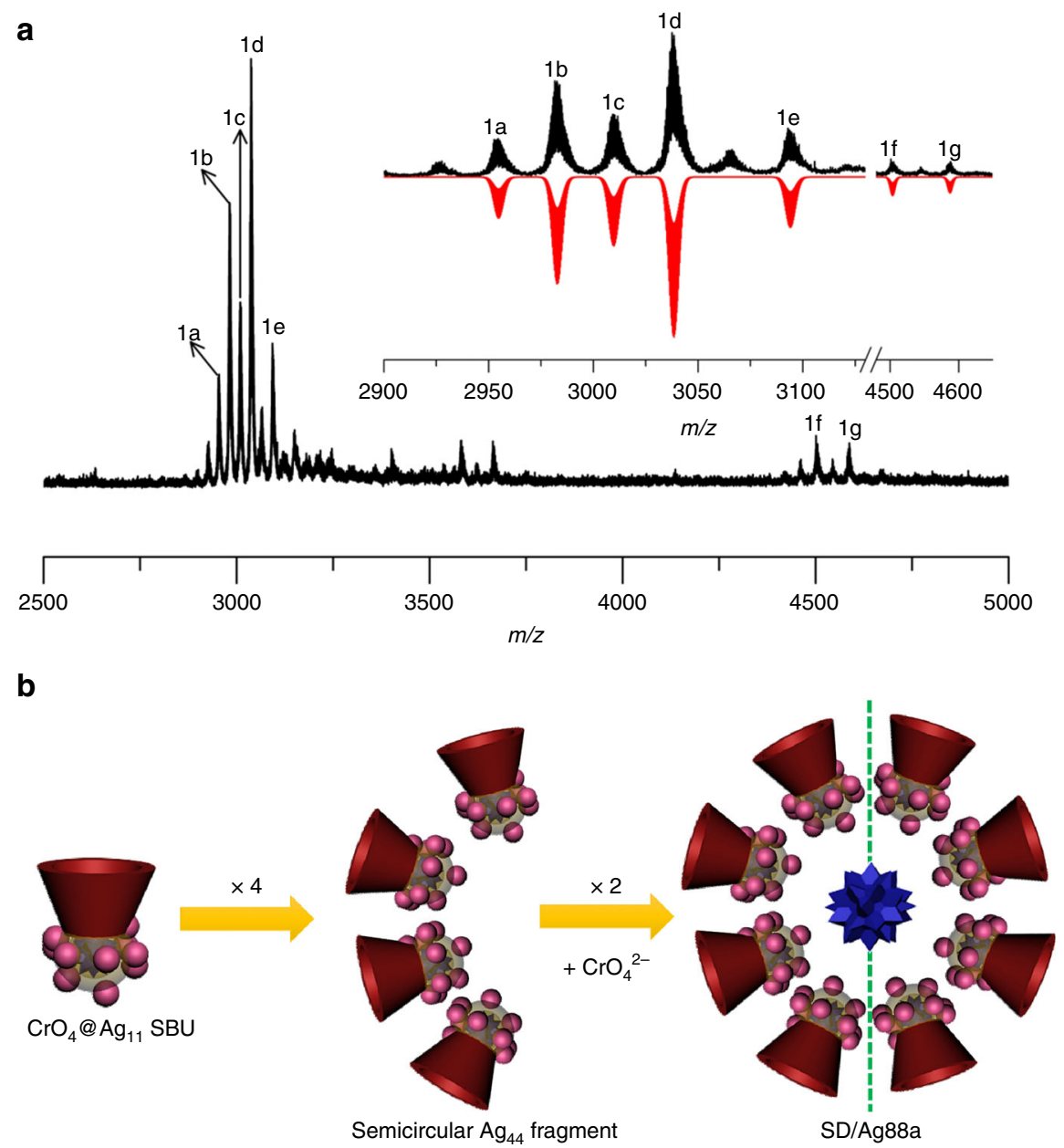

Fig. 5 Positive-ion ESI-MS and proposed solution assembly mechanism of SD/Ag88a. a Positive-ion ESI-MS of SD/Ag88a dissolved in $\mathrm{CH}_{2} \mathrm{Cl}_{2}$. Inset: the expanded experimental and simulated isotope-distribution patterns of 1a-1g. $\mathbf{b}$ The proposed solution assembly mechanism for SD/Ag88a.

kept after ten on/off cycles, suggesting the response reproducibility. The generation of photocurrent may involve photoinduced charge migration from $S 3 p$ to the Ag $5 s$ orbits.

The stability of the electrode was further proved by the compared IR spectra and PXRD patterns. ${ }^{48}$ After the photocurrent tests, both IR spectra (Supplementary Figs. 11, 12) and PXRD patterns (Supplementary Figs. 13, 14) of samples were basically identical to those of original samples, which indicates that these samples did not undergo decomposition in the process of electrode preparation and during the photocurrent measurements.

\section{Discussion}

In summary, we have assembled and characterized a silverorganic super calix comprising 88 silver atoms and $8 \mathrm{TC}^{4} \mathrm{~A}^{4-}$ ligands. SD/Ag88a is the highest-nuclearity metal cluster based on $\mathrm{TC}^{4} \mathrm{~A}^{4-}$. Structural analysis revealed important chromatetemplated $\mathrm{Ag}_{11}$ SBUs, which are further fused into a super calix of SD/Ag88a with a remaining $\mathrm{CrO}_{4}{ }^{2-}$ sitting on the center. Both local and global anion-templating effects from chromates are clearly manifested in the hierarchical structure of SD/Ag88a. The hierarchical assembly mechanism from bowl-like $\mathrm{Ag}_{11} \mathrm{SBU}$, a semicircular $\mathrm{Ag}_{44}$ fragment to the final circular $\mathrm{Ag}_{88}$ super calix was also revealed by using electrospray mass spectrometry (ESIMS). The successful installation of TC4 $\mathrm{A}^{4-}$ ligand on silver nanocluster exemplifies its powerful chelating ability and macrocyclic effects, which surely open a bright road to assembly of silver nanoclusters using such kind of macrocyclic ligands.

\section{Methods}

Synthesis of SD/Ag88a. Method A: the mixture of (EtSAg) ${ }_{n}(0.05 \mathrm{mmol}, 8.5 \mathrm{mg})$, $\mathrm{H}_{4}$ TC4A $(0.015 \mathrm{mmol}, 10.8 \mathrm{mg})$, and $\mathrm{K}_{2} \mathrm{Cr}_{2} \mathrm{O}_{7}(0.025 \mathrm{mmol}, 7.3 \mathrm{mg})$ were dissolved in mixed solvent of acetonitrile, dichloromethane, and $N, N^{\prime}$-dimethylformamide $(6.5 \mathrm{~mL}, \mathrm{v}: \mathrm{v}: \mathrm{v}=10: 2: 1)$. The mixed solution was stirred for $1 \mathrm{~h}$ at room temperature, then AgOAc $(0.1 \mathrm{mmol}, 16.7 \mathrm{mg})$ was added to the above mixture for another $3 \mathrm{~h}$ of stirring. The red solution was filtrated and evaporated in the dark for 2 weeks. The red prism crystals of SD/Ag88a were obtained in a yield of $10 \%$.

Synthesis of SD/Ag88a. Method B: the mixture of (EtSAg $)_{n}(0.05 \mathrm{mmol}, 8.5 \mathrm{mg})$, $\mathrm{H}_{4} \mathrm{TC} 4 \mathrm{~A}(0.015 \mathrm{mmol}, 10.8 \mathrm{mg})$, and $\mathrm{K}_{2} \mathrm{Cr}_{2} \mathrm{O}_{7}(0.025 \mathrm{mmol}, 7.3 \mathrm{mg})$ were dissolved in mixed solvent of acetonitrile, dichloromethane, and $N, N^{\prime}$-dimethylformamide $(6.5 \mathrm{~mL}, \mathrm{v}: \mathrm{v}: \mathrm{v}=10: 2: 1)$. The mixed solution was stirred for $1 \mathrm{~h}$ at room temperature. To this solution $\mathrm{AgOAc}(0.1 \mathrm{mmol}, 16.7 \mathrm{mg})$ was added. The reaction continued for further $3 \mathrm{~h}$ of stirring, then the red mixture was sealed in a $25-\mathrm{mL}$ Teflon-lined reaction vessel and kept at $65^{\circ} \mathrm{C}$ for $2000 \mathrm{~min}$. After cooling to room temperature, the red solution was filtrated and evaporated in the dark for 1 week. The red prism crystals of SD/Ag88a were isolated in a yield of $40 \%$. Elemental analyses calc. (found) for SD/Ag88a $\left(\mathrm{C}_{428} \mathrm{H}_{588} \mathrm{Ag}_{88} \mathrm{Cr}_{9} \mathrm{~K}_{2} \mathrm{~N}_{12} \mathrm{O}_{88} \mathrm{~S}_{64}\right)$ : C, 26.50 (26.51); H, 3.06 (3.08); N 0.87 (0.85)\%. Selected IR peaks $\left(\mathrm{cm}^{-1}\right): 3382(\mathrm{w}), 2949$ (w), $1658(\mathrm{w}), 1550(\mathrm{w}), 1434(\mathrm{~s}), 1301(\mathrm{w}), 1245(\mathrm{~m}), 1209(\mathrm{w}), 848(\mathrm{~m}), 828(\mathrm{~s})$, $760(\mathrm{~m}), 724(\mathrm{~m}), 650(\mathrm{w}), 612(\mathrm{w}), 540(\mathrm{w}), 520(\mathrm{w})$.

Synthesis of SD/Ag88b. The synthesis conditions were similar to those described for Method B above, but using AgOAc $(0.1 \mathrm{mmol}, 16.7 \mathrm{mg})$ and $\mathrm{AgSbF}_{6}(0.05$ $\mathrm{mmol}, 17.2 \mathrm{mg}$ ) instead. Red prism crystals of $\mathbf{S D} / \mathbf{A g 8 8 b}$ were isolated in a yield of $37 \%$. Elemental analyses calc. (found) for SD/Ag88b $\left(\mathrm{C}_{418} \mathrm{H}_{563} \mathrm{Ag}_{88} \mathrm{Cr}_{9-}\right.$ $\left.\mathrm{K}_{2} \mathrm{~N}_{9} \mathrm{O}_{84} \mathrm{~S}_{64}\right)$ : C, 26.22 (26.14); H, 2.96 (3.00); N $0.66(0.59) \%$. Selected IR peaks 


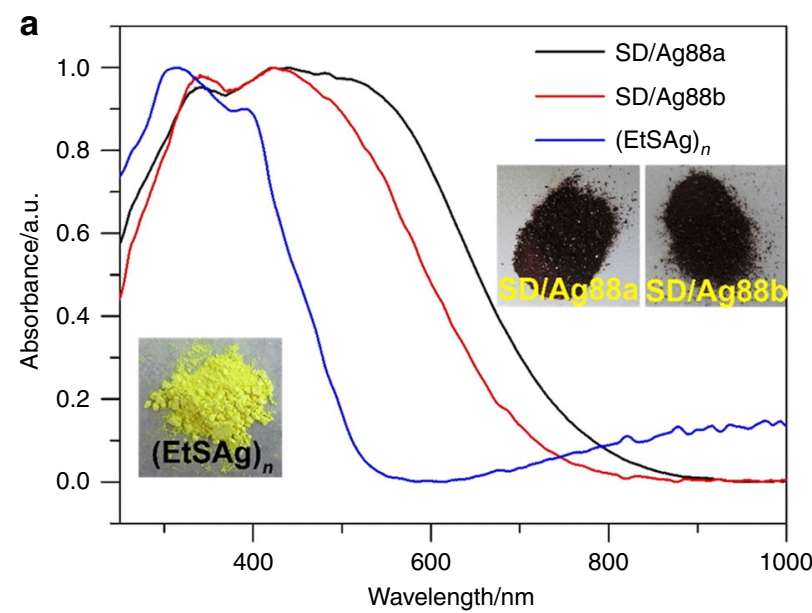

b

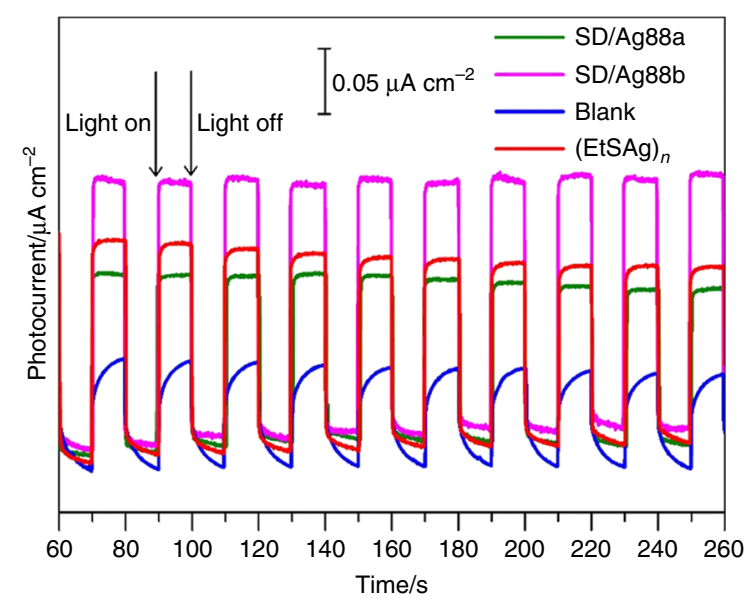

Fig. 6 The UV-Vis spectra and photocurrent responses of SD/Ag88a and SD/Ag88b. a The normalized UV-Vis spectra of SD/Ag88a, SD/Ag88b, and $(E t S A g)_{n}$ precursor in the solid state. Insets are the digital photographs of SD/Ag88a, SD/Ag88b, and (EtSAg) $n$ taken under the ambient environment. $\mathbf{b}$ Compared photocurrent responses of blank, (EtSAg) ${ }_{n}$, SD/ Ag88a, and SD/Ag88b ITO electrodes in a $0.2 \mathrm{M} \mathrm{Na}_{2} \mathrm{SO}_{4}$ aqueous solution under repetitive irradiation.

$\left(\mathrm{cm}^{-1}\right)$ : 2949 (w), 1549 (w), 1472 (w), 1433 (s), $1356(\mathrm{~m}), 1304(\mathrm{~m}), 1239(\mathrm{~m}), 1051$ (w), $966(\mathrm{w}), 855(\mathrm{~m}), 830(\mathrm{~s}), 764(\mathrm{~m}), 720(\mathrm{~m}), 648(\mathrm{w}), 528(\mathrm{w})$.

\section{Data availability}

The data that support the findings of this study are available from the corresponding author upon reasonable request. The X-ray crystallographic coordinates for structures reported in this article have been deposited at the Cambridge Crystallographic Data Centre, under deposition number CCDC: 1920453 and 1920454 for SD/Ag88a and SD/ Ag88b. These data can be obtained free of charge from the Cambridge Crystallographic Data Centre via www.ccdc.cam.ac.uk/data_request/cif.

Received: 8 July 2019; Accepted: 15 November 2019;

Published online: 16 January 2020

\section{References}

1. Jin, R., Zeng, C., Zhou, M. \& Chen, Y. Atomically precise colloidal metal nanoclusters and nanoparticles: fundamentals and opportunities. Chem. Rev. 116, 10346-10413 (2016).

2. Liu, Y., Najafabadi, B. K., Fard, M. A. \& Corrigan, J. F. A functionalized $\mathrm{Ag}_{2} \mathrm{~S}$ molecular architecture: facile assembly of the atomically precise ferrocene- decorated nanocluster $\left[\mathrm{Ag}_{74} \mathrm{~S}_{19}(\mathrm{dppp})_{6}\left(\mathrm{fc}\left(\mathrm{C}\{\mathrm{O}\} \mathrm{OCH}_{2} \mathrm{CH}_{2} \mathrm{~S}\right)_{2}\right)_{18}\right]$. Angew. Chem. Int. Ed. 54, 4832-4835 (2015).

3. Dhayal, R. S. et al. $\mathrm{Ag}_{21}\left\{\mathrm{~S}_{2} \mathrm{P}(\mathrm{OiPr})_{2}\right\}_{12}{ }^{+}$: an eight-electron superatom. Angew. Chem. Int. Ed. 54, 3702-3706 (2015).

4. Hau, S. C. K., Cheng, P.-S. \& Mak, T. C. W. Enlargement of globular silver alkynide cluster via core transformation. J. Am. Chem. Soc. 134, 2922-2925 (2012).

5. Chakraborty, I. \& Pradeep, T. Atomically precise clusters of noble metals: emerging link between atoms and nanoparticles. Chem. Rev. 117, 8208-8271 (2017).

6. Kurasawa, M., Arisaka, F. \& Ozeki, T. Asymmetrically fused polyoxometalatesilver alkynide composite cluster. Inorg. Chem. 54, 1650-1654 (2015).

7. Shen, H. \& Mizuta, T. An alkynyl-stabilized $\mathrm{Pt}_{5} \mathrm{Ag}_{22}$ cluster featuring a twodimensional alkynyl-platinum "crucifix motif". Chem.-Eur. J. 23, 17885-17888 (2017).

8. Li, G., Lei, Z. \& Wang, Q.-M. Luminescent molecular Ag-S nanocluster $\left[\mathrm{Ag}_{62} \mathrm{~S}_{13}\left(\mathrm{SBu}^{t}\right)_{32}\right]\left(\mathrm{BF}_{4}\right)_{4}$. J. Am. Chem. Soc. 132, 17678-17679 (2010).

9. Xie, Y.-P., Jin, J.-L., Lu, X. \& Mak, T. C. W. High-nuclearity silver thiolate clusters constructed with phosphonates. Angew. Chem. Int. Ed. 54, 15176-15180 (2015).

10. Wang, Z.-Y. et al. Atomically precise site-specific tailoring and directional assembly of superatomic silver nanoclusters. J. Am. Chem. Soc. 140, 1069-1076 (2018).

11. Yang, H. et al. Plasmonic twinned silver nanoparticles with molecular precision. Nat. Commun. 7, 12809 (2016).

12. Jin, S. et al. Crystal structure and optical properties of the $\left[\mathrm{Ag}_{62} \mathrm{~S}_{12}\left(\mathrm{SBu}^{t}\right)_{32}\right]^{2+}$ nanocluster with a complete face-centered cubic kernel. J. Am. Chem. Soc. 136, 15559-15565 (2014).

13. Gao, G.-G., Cheng, P.-S. \& Mak, T. C. W. Acid-induced surface functionalization of polyoxometalate by enclosure in a polyhedral silveralkynyl cage. J. Am. Chem. Soc. 131, 18257-18259 (2009).

14. Corrigan, J. F., Fuhr, O. \& Fenske, D. Metal chalcogenide clusters on the border between molecules and materials. Adv. Mater. 21, 1867-1871 (2009)

15. Anson, C. E. et al. Synthesis and crystal structures of the ligand-stabilized silver chalcogenide clusters $\left[\mathrm{Ag}_{154} \mathrm{Se}_{77}(\mathrm{dppxy})_{18}\right]$, $\left[\mathrm{Ag}_{320}(\mathrm{StBu})_{60} \mathrm{~S}_{130}(\mathrm{dppp})_{12}\right],\left[\mathrm{Ag}_{352} \mathrm{~S}_{128}\left(\mathrm{StC}_{5} \mathrm{H}_{11}\right)_{96}\right]$, and $\left[\mathrm{Ag}_{490} \mathrm{~S}_{188}\left(\mathrm{StC}_{5} \mathrm{H}_{11}\right)_{114}\right]$. Angew. Chem. Int Ed. 47, 1326-1331 (2008).

16. Vilar, R. Anion-templated synthesis. Angew. Chem. Int. Ed. 42, 1460-1477 (2003).

17. Campos-Fernandez, C. S. et al. Anion template effect on the self-assembly and interconversion of metallacyclophanes. J. Am. Chem. Soc. 127, 12909-12923 (2005).

18. Wang, Q.-M., Lin, Y.-M. \& Liu, K.-G. Role of anions associated with the formation and properties of silver clusters. Acc. Chem. Res. 48, 1570-1579 (2015).

19. Rais, D. et al. Anion-templated syntheses of rhombohedral silver-alkynyl cage compounds. Angew. Chem. Int Ed. 40, 3464-3467 (2001).

20. Wang, Z. et al. Johnson solids: anion-templated silver thiolate clusters capped by sulfonate. Chem.-Eur. J. 24, 1640-1650 (2018).

21. Li, X.-Y. et al. A platonic solid templating Archimedean solid: an unprecedented nanometre-sized $\mathrm{Ag}_{37}$ cluster. Nanoscale 7, 8284-8288 (2015).

22. Wang, Z. et al. Assembly of silver trigons into a buckyball-like $\mathrm{Ag}_{180}$ nanocage. Proc. Natl Acad. Sci. USA 114, 12132-12137 (2017).

23. Kumar, R., Lee, Y. O., Bhalla, V., Kumar, M. \& Kim, J. S. Recent developments of thiacalixarene based molecular motifs. Chem. Soc. Rev. 43, 4824-4870 (2014).

24. Liu, M., Liao, W., Hu, C., Du, S. \& Zhang, H. Calixarene-based nanoscale coordination cages. Angew. Chem. Int. Ed. 51, 1585-1588 (2012).

25. Bi, Y., Du, S. \& Liao, W. p-tert-Butylthiacalix[4]arene-supported highnuclearity $\left\{\mathrm{Co}_{24} \mathrm{M}_{8}\right\}(\mathrm{M}=\mathrm{Mo}$ or $\mathrm{W})$ nanospheres and the hybrids with Keggin polyoxometalates. Chem. Commun. 47, 4724-4726 (2011).

26. Bi, Y., Wang, S., Liu, M., Du, S. \& Liao, W. A tetragonal prismatic $\left\{\mathrm{Co}_{32}\right\}$ nanocage based on thiacalixarene. Chem. Commun. 49, 6785-6787 (2013).

27. Geng, D. et al. Merohedral icosahedral $\mathrm{M}_{48}\left(\mathrm{M}=\mathrm{Co}^{\mathrm{II}}, \mathrm{Ni}^{\mathrm{II}}\right)$ cage clusters supported by thiacalix[4]arene. Chem. Sci. 9, 8535-8541 (2018).

28. Bi, Y., Du, S. \& Liao, W. Thiacalixarene-based nanoscale polyhedral coordination cages. Coord. Chem. Rev. 276, 61-72 (2014).

29. $\mathrm{Bi}$, Y. et al. A $\left\{\mathrm{Co}_{32}\right\}$ nanosphere supported by $p$-tert-butylthiacalix[4]arene. J. Am. Chem. Soc. 131, 11650-11651 (2009).

30. Hang, X. et al. Discrete $\left\{\mathrm{Ni}_{40}\right\}$ coordination cage: a calixarene-based Johnsontype $\left(J_{17}\right)$ hexadecahedron. J. Am. Chem. Soc. 138, 2969-2972 (2016).

31. Wang, $\mathrm{S}$. et al. Calixarene-based $\left\{\mathrm{Ni}_{18}\right\}$ coordination wheel: highly efficient electrocatalyst for the glucose oxidation and template for the homogenous cluster fabrication. J. Am. Chem. Soc. 140, 6271-6277 (2018).

32. $\mathrm{Su}, \mathrm{K}$. et al. Open pentameric calixarene nanocage. Inorg. Chem. 53, 18-20 (2014).

33. Xiong, K. C. et al. Chlorine-induced assembly of a cationic coordination cage with a $\mu_{5}$-carbonato-bridged $\mathrm{Mn}_{24} \mathrm{II}_{2}$ core. Chem. Eur. J. 18, 5536-5540 (2012). 
34. Guan, Z.-J. et al. Thiacalix 4 arene: new protection for metal nanoclusters. Sci. Adv. 2, e1600323 (2016).

35. Guan, Z.-J. et al. The stability enhancement factor beyond eight-electron shell closure in thiacalix 4 arene-protected silver clusters. Chem. Sci. 10, 3360-3365 (2019).

36. Liu, J.-W. et al. Anisotropic assembly of $\mathrm{Ag}_{52}$ and $\mathrm{Ag}_{76}$ nanoclusters. J. Am. Chem. Soc. 140, 1600-1603 (2018).

37. Wang, Z. et al. Trapping an octahedral $\mathrm{Ag}_{6}$ kernel in a seven-fold symmetric $\mathrm{Ag}_{56}$ nanowheel. Nat. Commun. 9, 2094 (2018)

38. Liu, H. et al. Acid-base-triggered structural transformation of a polyoxometalate core inside a dodecahedrane-like silver thiolate shell. Angew. Chem. Int. Ed. 55, 3699-3703 (2016).

39. Liu, J.-W. et al. A giant 90 -nucleus silver cluster templated by hetero-anions. Chem. Commun. 54, 4461-4464 (2018).

40. Zhang, S.-S. et al. Anion-templated nanosized silver alkynyl clusters: cluster engineering and solution behavior. Chem.-Eur. J. 23, 3432-3437 (2017)

41. Wang, Z., Su, H.-F., Tung, C.-H., Sun, D. \& Zheng, L.-S. Deciphering synergetic core-shell transformation from $\left[\mathrm{Mo}_{6} \mathrm{O}_{22} @ \mathrm{Ag}_{44}\right]$ to $\left[\mathrm{Mo}_{8} \mathrm{O}_{28} @ \mathrm{Ag}_{50}\right]$. Nat. Commun. 9, 4407 (2018).

42. Xiong, K. et al. Truncated octahedral coordination cage incorporating six tetranuclear-metal building blocks and twelve linear edges. Chem. Sci. 3, 2321-2325 (2012).

43. Huang, R.-W. et al. Tandem silver cluster isomerism and mixed linkers to modulate the photoluminescence of cluster-assembled materials. Angew. Chem. Int. Ed. 57, 8560-8566 (2018).

44. Li, S. et al. Atom-precise modification of silver(I) thiolate cluster by shell ligand substitution: a new approach to generation of cluster functionality and chirality. J. Am. Chem. Soc. 140, 594-597 (2018).

45. Schmidbaur, H. \& Schier, A. Argentophilic interactions. Angew. Chem. Int. Ed. 54, 746-784 (2015).

46. Wei, $\mathrm{Y}$. et al. $\mathrm{Pb}(\mathrm{II})$ metal-organic nanotubes based on cyclodextrins: biphasic synthesis, structures and properties. Chem. Sci. 3, 2282-2287 (2012).

47. $\mathrm{Wu}$, T. et al. Monocopper doping in Cd-In-S supertetrahedral nanocluster via two-wtep strategy and enhanced photoelectric response. J. Am. Chem. Soc. 135, 10250-10253 (2013).

48. Wang, C., Liu, C., Li, L.-J. \& Sun, Z.-M. Synthesis, crystal structures, and photochemical properties of a family of heterometallic titanium oxo clusters. Inorg. Chem. 58, 6312-6319 (2019).

\section{Acknowledgements}

This work was financially supported by the National Natural Science Foundation of China (Grant Nos. 21822107, 91961105, 21571115, and 21827801), the Natural Science Foundation of Shandong Province (Nos. JQ201803, ZR2019ZD45, and ZR2017MB061), the Taishan Scholar Project of Shandong Province of China (Nos. tsqn201812003 and ts20190908), the Qilu Youth Scholar Funding of Shandong University, and the Fundamental Research Funds of Shandong University (104.205.2.5).

\section{Author contributions}

The original idea was conceived by D.S., experiments and data analyses were performed by Z.W., Y.-W.G., Q.-P.Q., and D.S., ESI-MS data were collected by H.-F.S., structure characterization was performed by Z.W., Y.F.B., and D.S., and the paper was drafted by D.S., Z.W., C.-H.T., and L.-S.Z. All authors have given approval to the paper.

\section{Competing interests}

The authors declare no competing interests.

\section{Additional information}

Supplementary information is available for this paper at https://doi.org/10.1038/s41467019-13682-5.

Correspondence and requests for materials should be addressed to D.S.

Peer review information Nature Communications thanks Aude Demessence and the other, anonymous, reviewer(s) for their contribution to the peer review of this work. Peer reviewer reports are available.

Reprints and permission information is available at http://www.nature.com/reprints

Publisher's note Springer Nature remains neutral with regard to jurisdictional claims in published maps and institutional affiliations.

\section{(c) (i)}

Open Access This article is licensed under a Creative Commons Attribution 4.0 International License, which permits use, sharing, adaptation, distribution and reproduction in any medium or format, as long as you give appropriate credit to the original author(s) and the source, provide a link to the Creative Commons license, and indicate if changes were made. The images or other third party material in this article are included in the article's Creative Commons license, unless indicated otherwise in a credit line to the material. If material is not included in the article's Creative Commons license and your intended use is not permitted by statutory regulation or exceeds the permitted use, you will need to obtain permission directly from the copyright holder. To view a copy of this license, visit http://creativecommons.org/ licenses/by/4.0/.

(C) The Author(s) 2020 